\title{
Hatching dynamics of the beet cyst nematode, Heterodera schachtii, following exposure to root leachates from cultivars of sugar beet, white mustard and radish
}

by Wright, A.J.D., Sparkes, D.L., Stevens, M. and Back, M.A.

Copyright, Publisher and Additional Information: This is the authors' accepted manuscript. The final published version (version of record) is available online via Brill

Please refer to any applicable terms of use of the publisher.

DOI: $\underline{\text { https://doi.org/10.1163/15685411-00003256 }}$

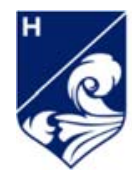

Harper Adams University

Wright, A.J.D., Sparkes, D.L., Stevens, M. and Back, M.A. 2019. Hatching dynamics of the beet cyst nematode, Heterodera schachtii, following exposure to root leachates from cultivars of sugar beet, white mustard and radish. Nematology. 
Hatching dynamics of Heterodera schachtii

Hatching dynamics of the beet cyst nematode, Heterodera schachtii, following exposure to root leachates from cultivars of sugar beet, white mustard and radish

Alistair J. D. Wright ${ }^{1,2}$, Debbie L. SpARKes ${ }^{1}$, Mark SteVEnS ${ }^{2}$ \& Matthew A. BACK ${ }^{3, *}$

${ }^{1}$ Division of Agricultural \& Environmental Sciences, School of Biosciences, University of Nottingham, Sutton Bonington Campus, Loughborough, Leicestershire, UK

${ }^{2}$ The British Beet Research Organisation, the Innovation Centre, Norwich Research Park, Norwich, UK

${ }^{3}$ Centre for Integrated Pest Management, Harper Adams University, Newport, Shropshire, $U K$

Received: 10 September 2018; revised: 4 March 2019 Accepted for publication: 5 March 2019

* Corresponding author - email: mback@harper-adams.ac.uk 
Summary - The hatching and emergence of juveniles from cysts of Heterodera schachtii in response to various stimuli is well understood. These responses relate to means of optimising the chances of successful reproduction and survival of populations. However, the effect of different cultivars of host species is not so well understood. To gain a further understanding of any differences between cultivars of host species, we conducted a number of experiments using root leachates obtained from a range of cultivars of sugar beet (Beta vulgaris), radish (Raphanus sativus) and white mustard (Sinapis alba). Heterodera schachtii cysts were exposed to root leachate solutions in in vitro laboratory assays during which juvenile emergence from cysts was monitored weekly. Significant differences in the stimulation of hatch of juveniles were found in response to different sugar beet cultivars and these differences may be driven by differing growth habits of such varieties. However, results obtained from experiments using brassica varieties showed contrasting responses to each other. In one experiment, root leachates appeared to inhibit hatch of juveniles. However, two experiments did show a stimulation of hatch of juveniles and also significant differences in hatch responses due to the age of the plant. These findings may help develop future screening procedures for brassica trap crops and help identify those that show the greatest potential for H. schachtii control.

Keywords - Beta vulgaris, hatch stimulation, integrated pest management, Raphanus sativus, Sinapis alba. 
The beet cyst nematode, Heterodera schachtii (Schmidt), is a major pest of sugar beet (Beta vulgaris L.) crops around the world (Müller, 1999) and can cause yield losses of up to $60 \%$ in susceptible varieties (Cooke, 1987; Blok et al., 2018). It also has a wide host range (CABI, 2018) and can also cause damage to brassica crops such as oilseed rape (Brassica napus) (Kakaire et al., 2012). Careful management is required to monitor and limit yield losses caused by the nematode and prevent spread of infested soil to new fields.

The use of tolerant varieties of sugar beet in the management of $H$. schachtii infestations has become popular. Tolerant varieties are able to limit the yield losses caused by the feeding nematodes, although these varieties do not limit population multiplication (Hauer et al., 2016; Reuther et al., 2017). Varieties with tolerance are now widely available across European markets and are recommended for use in H. schachtii infested fields (BBRO, 2018). Tolerant varieties are favoured by growers since they yield better than $H$. schachtii resistant (ones that actively lower $H$. schachtii populations) cultivars of sugar beet, which experience a yield drag (Märländer et al., 2003; Dewar \& Cooke, 2006). Another popular method of control is the use of a resistant trap crop (Cooke, 1985; Müller, 1999; Hauer et al., 2016). Trap crops for control of $H$. schachtii consist of varieties of radish (Raphanus sativus) or white mustard (Sinapis alba), which are commonly planted in infested fields during the summer prior to sugar beet cultivation (usually immediately after harvest of the previous crop) and are intended to reduce the populations of $H$. schachtii in the soil, ahead of the sugar beet planting. These trap crops are tested using bioassays to determine their resistance characteristics using hatched secondstage juveniles (J2) of H. schachtii (Bundessortenamt, 2014; Hauer et al., 2016). Therefore, the ability of these varieties to stimulate the hatch of $\mathrm{J} 2$ is not typically assessed. This study aimed to assess the hatching dynamics of a range of these brassica trap crop varieties.

Hatching in cyst nematodes is a complex process that varies between species of nematodes and their host plants. A thorough review of this topic has recently been made 
(Masler \& Perry, 2018). With regard to H. schachtii hatching responses, four distinct types of dormancy have been found (Zheng \& Ferris, 1991). This dormancy delays the hatch of the J2 within a cyst and these increase the chances of some of the juveniles finding a suitable host and then reproducing. Perry (2002) classified H. schachtii as possessing a hatch response that results in very large numbers of $\mathrm{J} 2$ reacting to host root leachates but also having a large level of hatch in response to water only. This is in contrast with other cyst nematode species, such as the potato cyst nematodes (Globodera pallida and G. rostochiensis), where hatching is modulated by a variety of hatching factors associated with the root leachates of potatoes with very few J2 hatching in response to water (Evans, 1983; Perry, 2002). In the case of $H$. schachtii, the various hatch responses cause some $\mathrm{J} 2$ to hatch soon after developing and others remain dormant until a suitable host is detected and, as a result, approximately $50 \%$ of a cyst's contents hatch every year (Jones, 1956; Zheng \& Ferris, 1991). It is for this reason that a period of approximately 5 years between a host species being grown in an infested field can keep $H$. schachtii populations below damaging levels in sugar beet crops (Koch \& Gray, 1997; BBRO, 2009). Where cultivation of sugar beet is required to be more frequent than recommended, or growers' rotations include other host species, the use of the resistant brassicas may be a useful tool in controlling $H$. schachtii damage to future crops.

It is also important to consider whether different varieties of sugar beet stimulate significantly different amounts of hatch of $H$. schachtii $\mathrm{J} 2$ as a cultivar that results in reduced initial levels of hatch may be less prone to damage from invading J2. Previous studies usually have included just one or two examples of commercial varieties of host species being investigated (Steele et al., 1982; Cooke, 1985; Kakaire et al., 2015). Therefore, differences that may exist between the different variety types have not been investigated in detail. Different $H$. schachtii hatching responses to various cultivars of the same species have previously been 
identified in oilseed rape (Fatemy \& Abootorabi, 2002) and we hypothesise that different cultivars of other host crops may also vary in their ability to stimulate juvenile hatch.

We set out to understand how a range of modern cultivars of sugar beet, radish and one cultivar of white mustard may differ in their ability to stimulate hatch of $\mathrm{J} 2 \mathrm{of} H$. schachtii and whether these differences could be related to their reported tolerance, resistance or susceptibility to $H$. schachtii. To achieve these aims we performed a series of in vitro experiments, which are reported in this manuscript.

\section{Materials and methods}

A total of four experiments were conducted to test the influence of leachates obtained from different varieties of sugar beet, radish and mustard (Table 1) upon the hatching dynamics of H. schachtii. Experiment 1 assessed the level of hatch stimulated from twelve varieties of radish, nine of which are resistant to $H$. schachtii. It also included one resistant variety of white mustard. Experiment 2 tested $H$. schachtii hatching responses to nine varieties of sugar beet, which varied in their susceptibility to $H$. schachtii. Experiment 3 combined both brassica and sugar beet treatments again to investigate hatching responses. Three resistant varieties of radish, the resistant mustard and a susceptible radish were grown alongside six varieties of sugar beet. Some of the sugar beet varieties had been used in Experiment 2 and some were newer varieties (BBRO, 2015). All brassica treatments had been previously grown in Experiment 1. Experiment 4 replicated only the brassica treatments from Experiment 3. However, the plants were grown for 5, 6 and 7 weeks to investigate the effect of age of the plants upon the stimulation of hatch 
Table 1 - List of treatments used in the hatch experiments. Radish and mustard treatments are listed with their corresponding resistance class, and sugar beet treatments with their reported variety type as recommended by their breeders.

\begin{tabular}{|c|c|c|c|}
\hline Treatment & Variety & $\begin{array}{l}\text { Resistance } \\
\text { class* }\end{array}$ & Experiments \\
\hline 1 & 'Colonel' & 1 & $1,3,4$ \\
\hline 2 & 'Decapo' & 2 & 1 \\
\hline 3 & 'Defender' & 2 & $1,3,4$ \\
\hline 4 & 'Melotop' & 2 & 1 \\
\hline 5 & 'Compass' & 2 & 1 \\
\hline 6 & 'Baracuda' & 2 & 1 \\
\hline 7 & 'Bokito' & 2 & $1,3,4$ \\
\hline 8 & 'Anaconda' & 2 & 1 \\
\hline 9 & 'Romessa' & 2 & 1 \\
\hline 10 & 'Siletina' & $N / A$ & 1 \\
\hline 11 & 'Silletta Nova' & $a^{\prime} \quad N / A$ & 1 \\
\hline 12 & $\begin{array}{l}\text { 'Early } \\
\text { Mino' }\end{array}$ & $\mathrm{N} / \mathrm{A}$ & $1,3,4$ \\
\hline \multicolumn{4}{|c|}{ Mustard (S. alba) } \\
\hline Treatment & Variety & $\begin{array}{l}\text { Resistance } \\
\text { class* }\end{array}$ & Experiments \\
\hline 13 & 'Accent' & 2 & $1,3,4$ \\
\hline
\end{tabular}

\begin{tabular}{llll}
\multicolumn{2}{l}{ Sugar Beet (B. vulgaris) } & \\
\hline Treatment & Variety & $\begin{array}{l}\text { Variety } \\
\text { Type }\end{array}$ & Experiments \\
\hline 14 & 'Sanetta' & $\mathrm{R}$ & 2 \\
15 & Coded Variety & $\mathrm{R}$ & 3 \\
16 & 'Aurora' & $\mathrm{T}$ & 2,3 \\
17 & 'Thor' & $\mathrm{T}$ & 2,3 \\
18 & 'Mongoose' & $\mathrm{T}$ & 2 \\
19 & 'Pamina' & $\mathrm{T}$ & 2 \\
20 & 'BTS 755' & $\mathrm{T}$ & 3 \\
21 & 'Maddox' & $\mathrm{LT}$ & 2,3 \\
22 & 'Sentinel' & $\mathrm{LT}$ & 2 \\
23 & 'Cayman' & $\mathrm{S}$ & 2 \\
24 & 'Pasteur' & $\mathrm{S}$ & $\mathrm{All}$
\end{tabular}

\begin{tabular}{lll} 
Controls & & \\
\hline Treatment & Type & Experiments \\
\hline 25 & Sand & All \\
26 & Deionised Water & All
\end{tabular}

* Resistance classes are measured under controlled tests in Germany before approval for cultivation (Bundessortenamt, 2014). Resistance class of $1 \geq 90 \%$ resistance and class $2=70$ to $90 \%$ resistance to $H$. schachtii.

+ Sugar beet varieties can be classed as Resistant (R), Tolerant (T), Light tolerant (LT) or Susceptible (S) to $H$. schachtii when tested in recommended list trial (BBRO, 2018) 


\section{ROOT LEACHATE COLLECTION}

For all experiments, seeds of each variety were planted into $9 \mathrm{~cm}$ diam., $350 \mathrm{ml}$ plastic plant pots filled with sterilised coarse sand. The plants were grown in triplicate at $20^{\circ} \mathrm{C}$ day, $16^{\circ} \mathrm{C}$ night with a $16 \mathrm{~h}$ photoperiod in a controlled environment room (CER). Plants were evenly watered using a dripper irrigation system and nutrition was provided using a complete fertiliser (Hortifeed standard 15-7-30, diluted $1 \mathrm{~g}$ to 11 water). Root leachates were collected from the plants after they had grown for 6 weeks (Experiments 1, 2 and 3). In Experiment 4, plants were grown for either 5, 6 or 7 weeks. Leachates were collected from the pots using a modified method of Shepherd (1970). The irrigation was removed and the pots were saturated with deionised water $24 \mathrm{~h}$ prior to leachate collection and conditions in the CER changed to $12^{\circ} \mathrm{C}$ in continuous dark. This was to allow the leachates to diffuse into the water and also reduce transpiration by the plants. The next day the pots were placed into a glass funnel over a beaker and then into the pot a further $200 \mathrm{ml}$ of deionised water was applied, which was passed through the pot three times, being topped up with extra water if necessary. As a result, $600 \mathrm{ml}$ of root leachate for each treatment was collected from the three replicates and they were combined to make one sample. A proportion of each sample was then filtered using a funnel and filter paper (Whatmann 113). Filtered leachate solution was then diluted 1:1 with additional deionised water and $100 \mathrm{ml}$ of each root leachate solution retained for use in the experiments. The diluted samples were stored at $3^{\circ} \mathrm{C}$ until needed for the hatching assay. For Experiment 1 , the leachates were stored for 8 weeks before starting the hatching assay. All of the other hatching assays began within 1 week of the root leachate solution (RLS) collection and preparation. Fresh RLS were prepared for each experiment.

HATCHING ASSAY SET-UP 
The hatching assays were set up using a modified method of Danquah et al. (2011). Plastic multi-well plates (with either 12 or 24 wells depending on the number of treatments for the experiment) were used. A blocked design was used with each plate used representing a block, with one replicate of each treatment per block. Into one well in each plate $2 \mathrm{ml}$ of the RLS was pipetted to which ten cysts were added inside baskets created from the wide end of 1 $\mathrm{ml}$ pipette tips onto which plastic netting (250 $\mu \mathrm{m}$ aperture) was fused using a heat plate and when filled the plates were then sealed with parafilm. Details of which varieties were used in each experiment can be seen in Table 1. The hatching assays ran for 6 weeks and during this time, the plates were kept in the dark inside a plastic box on the benchtop in the laboratory. A temperature logger (Tiny Tag Ultra 2, Gemini Data Loggers Ltd) was placed alongside the plates for the duration of the experiment to monitor temperature. For all experiments, temperatures were measured to be in the range of $20 \pm 4^{\circ} \mathrm{C}$. Each week the RLS was removed so that the number of hatched juveniles could be counted under a stereomicroscope (Leica M80, Leica Microsystems $\mathrm{GmbH}$ ) and $2 \mathrm{ml}$ of fresh RLS solution pipetted into the correct corresponding well.

After the 6 weeks had elapsed, the cysts were removed from the baskets and crushed to release the eggs and $\mathrm{J} 2$. The contents of the 10 cysts were diluted in $50 \mathrm{ml}$ of water. The water was then thoroughly agitated using a $10 \mathrm{ml}$ glass pipette and pipette controller (Powerpette, VWR International) and then $1 \mathrm{ml}$ of this solution was extracted and counted using the microscope to allow for the percentage $\mathrm{J} 2$ hatch to be determined.

All experiments contained five replicates of each treatment, except for the final experiment, which contained four replicates. The cysts used in the experiments had been recently cultured on oilseed rape (B. napus) for Experiments 1-3 and susceptible sugar beet (B. vulgaris) for Experiment 4. Cysts were obtained from the infested soil using a Wye Washer 
column elutriator (Winfield et al., 1987). Prior to extraction, the soil containing the cysts was stored at $3^{\circ} \mathrm{C}$ and kept moist. After extraction all of the cysts were cleaned in deionised water prior to being placed into the plates. Only cysts that appeared viable were used in the experiments with damaged, small or empty cysts being discarded. The population used for the cultures originated from a $H$. schachtii infested field site near Thetford, Norfolk, UK $\left(52^{\circ} 24^{\prime}\right.$ 22.2156" N 051' 4.3992" E).

DATA ANALYSIS

All data were analysed using ANOVA in GenStat $17^{\text {th }}$ Edition (VSN international, Hemel Hempstead, UK). Genstat was also used for calculation of least significant difference (LSD) values and also to conduct Duncan's multiple range test, both at 5\% significance. Data were then presented in graphical format using GraphPad Prism v.7 (GraphPad Software Inc. La Jolla, CA, USA).

Curve fitting was performed also using GraphPad Prism v.7. One phase association exponential curves were fitted to work out the hatching dynamic for each sample over time, $t$, using the following equation:

$$
Y=Y 0+(P l a t e a u-Y 0) \times(1-\exp (-K \times t))
$$

where $Y$ is the proportion of hatched $\mathrm{J} 2$, and $Y 0$ denotes the number of hatched $\mathrm{J} 2$ at $t 0$, i.e., zero. Plateau is point at which $Y$ becomes static and therefore hatching ceases. $K$ is the reaction rate constant, which is expressed in inverse days and is derived from the slope of the curve, and can be considered the hatching rate constant, hereby referred to as HR, of the response of the nematodes to the RLS. Faster hatching reactions to the RLS have a lower HR than slower 
nematode hatching reactions to the RLS. The HR value of each sample was then analysed by ANOVA. All curves were found to have an $\mathrm{R}^{2}$ value of $\geq 0.9$. Curves with ambiguous fits and that did not follow expected one phase association exponential curves were detected by the analysis software and excluded from further analysis (this occurred for fewer than $1 \%$ of the curves analysed).

\section{Results}

EXPERIMENT 1 - BRASSICA HATCH RESPONSES

Exposure of $H$. schachtii to deionised water resulted in the greatest HR, which was significantly higher than treatments R10 and R5. RLS treatment R7 (Table 2), which had the lowest observed level of hatch of any treatment (Fig. 1), was not significantly different to the deionised water control.

Hatching of all treatments increased each week, with the greatest hatch occurring during the first half of the bioassay (Fig. 1). When the combined total hatch were compared, the deionised water control clearly stimulated the greatest levels of hatch at $30 \%(P<0.001)$. Mean hatch for all brassica RLS treatments was $10.9 \%$ and all treatments were similar to each other except for a significant difference detected between R12 (19.3\%) and R7 (3.8\%). The sugar beet treatment (SB S 24) resulted in a total hatch of $20.4 \%$, which was similar to the deionised water control. The sand leachate control was found to have a significantly lower level of hatch than the deionised water.

As similar HR values were observed between almost all of the treatments (Table 2), Radish variety 5 , had the lowest HR and was significantly lower than brassica RLS treatments 1, 2, 4, 9 and $11(P<0.05)$. However, all of the other brassica RLS treatments had HR similar 


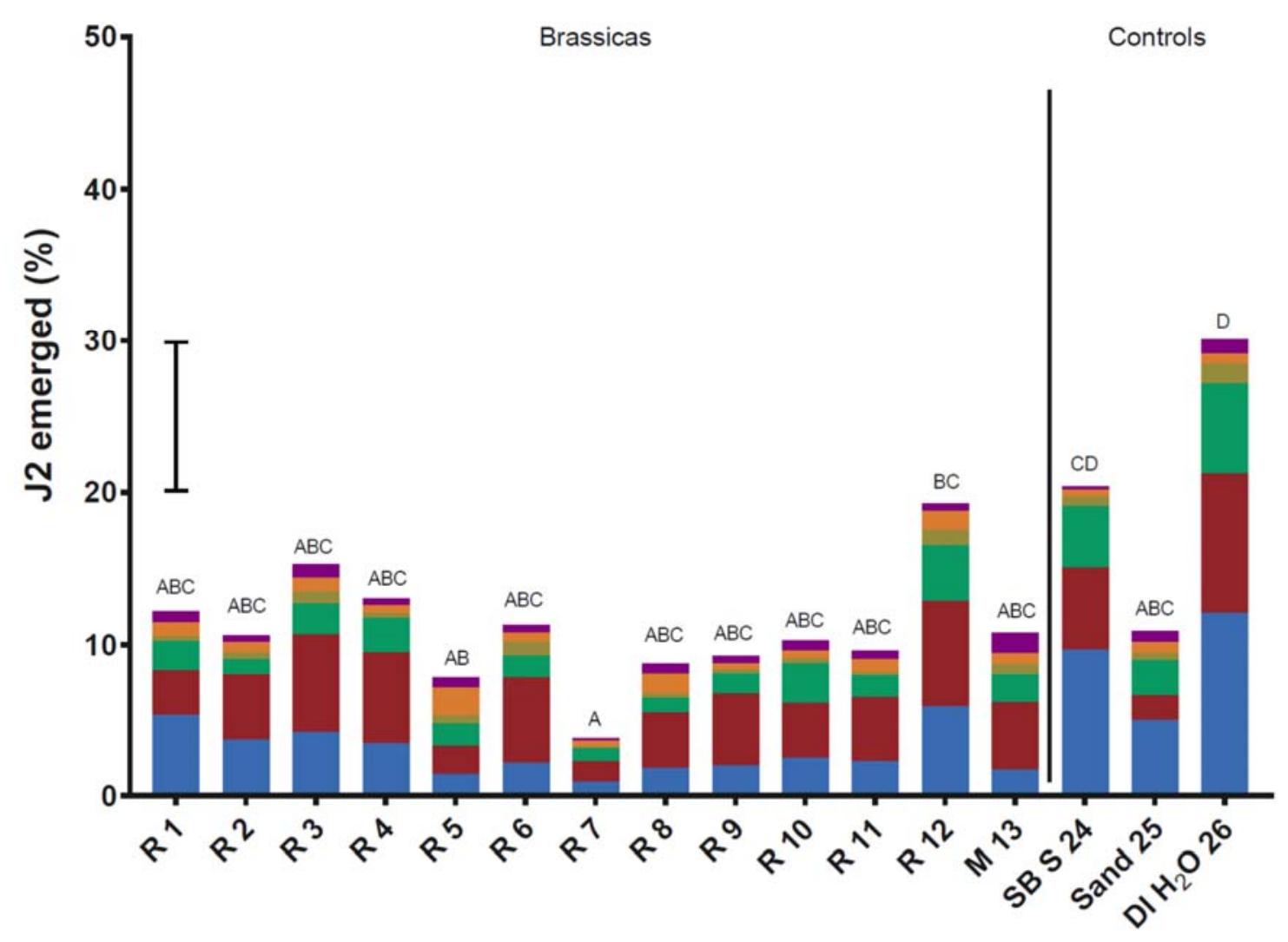

Treatment

Fig. 1. Results of experiment using brassica treatments after 6 weeks of exposure to root exudate solutions. Treatments are either of radish (Raphanus sativus) [R] or mustard (Sinapis alba) $[\mathrm{M}]$ and are labelled with their treatment number (Table 1). Control treatments of susceptible sugar beet (Beta vulgaris), sand leachate and deionised water are also included. The bars show the cumulative percentage hatch counted every 7 days $(\square 7, \square 14, \square 21, \square 28$, 35 and $\square 42$ days). Significant differences were found $(P<0.001)$ between the treatments. The error bar shows LSD at 5\% significance for the total percentage hatch recorded. Treatments with different letters show differences at 5\% significance according to Duncan's Multiple range test. 
Table 2 - Hatching rate (HR) for the responses of the hatching $H$. schachtii juveniles from cysts in response to root leachate solutions from brassicas (Experiment 1), sugar beet (Experiment 2) and a combination of brassicas and sugar beet (Experiment 3 ).

\begin{tabular}{|c|c|c|c|c|c|c|c|c|}
\hline Treatment & Treatment name & Species & Experime & t 1 & Experiment & & Experiment 3 & \\
\hline 1 & ‘Colonel' & R. sativus & 0.08346 & bc & - & & 0.1789 & $d$ \\
\hline 2 & ‘Decapo’ & R. sativus & 0.07242 & $\mathrm{bc}$ & - & & - & \\
\hline 3 & ‘Defender' & R. sativus & 0.06282 & $a b c$ & - & & 0.1608 & $c d$ \\
\hline 4 & ‘Melotop' & R. sativus & 0.07121 & bc & - & & - & \\
\hline 5 & 'Compass' & R. sativus & 0.02839 & a & - & & - & \\
\hline 6 & 'Baracuda' & R. sativus & 0.05631 & $a b c$ & - & & - & \\
\hline 7 & ‘Bokito' & R. sativus & 0.05675 & $a b c$ & - & & 0.1352 & $\mathrm{bcd}$ \\
\hline 8 & 'Anaconda' & R. sativus & 0.05536 & $a b c$ & - & & - & \\
\hline 9 & 'Romessa' & R. sativus & 0.06619 & bc & - & & - & \\
\hline 10 & 'Siletina' & R. sativus & 0.04969 & $a b$ & - & & - & \\
\hline 11 & 'Silletta Nova' & R. sativus & 0.08555 & bc & - & & - & \\
\hline 12 & ‘Early Mino' & R. sativus & 0.05758 & $a b c$ & - & & 0.1363 & $\mathrm{bcd}$ \\
\hline 13 & 'Accent' & S. $a l b a$ & 0.05233 & $a b c$ & - & & 0.1349 & $\mathrm{bcd}$ \\
\hline 14 & 'Sanetta' & B. vulgaris & - & & 0.02276 & a & - & \\
\hline 15 & ‘Coded Variety' & B. vulgaris & - & & - & & 0.0841 & $\mathrm{ab}$ \\
\hline 16 & 'Aurora' & B. vulgaris & - & & 0.02665 & a & 0.0631 & a \\
\hline 17 & ‘Thor’ & B. vulgaris & - & & 0.04302 & a & 0.0746 & $\mathrm{ab}$ \\
\hline 18 & ‘Mongoose' & B. vulgaris & - & & 0.02736 & $\mathrm{a}$ & - & \\
\hline 19 & ‘Pamina’ & B. vulgaris & - & & 0.03915 & a & - & \\
\hline 20 & 'BTS 755' & B. vulgaris & - & & - & & 0.0866 & $\mathrm{ab}$ \\
\hline 21 & ‘Maddox' & B. vulgaris & - & & 0.03078 & a & 0.1025 & $a b c$ \\
\hline 22 & 'Sentinel' & B. vulgaris & - & & 0.04697 & a & - & \\
\hline 23 & ‘Cayman’ & B. vulgaris & - & & 0.02826 & a & - & \\
\hline 24 & ‘Pasteur’ & B. vulgaris & 0.08215 & bc & 0.02525 & a & 0.066 & a \\
\hline 25 & Sand & & 0.07272 & bc & 0.1751 & c & 0.1367 & bcd \\
\hline 26 & Deionised water & & 0.08844 & c & 0.07148 & b & 0.1393 & bcd \\
\hline LSD & & & 0.03212 & & 0.02123 & & 0.05786 & \\
\hline$P$ & & & 0.012 & & $<0.001$ & & 0.001 & \\
\hline
\end{tabular}


to each other. These data imply that the varieties had similar HR responses to the RLS but had different levels of maximum hatch that they could achieve (Fig. 1), while all RLS treatments appeared to inhibit hatch compared to the deionised water control.

\section{EXPERIMENT 2 - SUGAR BEET HATCH RESPONSES}

The sugar beet RLS caused a similar HR response in $H$. schachtii, although this was significantly lower than both the water and sand controls, which themselves were different to each other $(P<0.001)$ (Table 2$)$.

As seen in Experiment 1, the greatest proportions of hatch occurred in the first 3 weeks of the experiment, although hatching increased each week during the first half of the experiment in most treatments (Fig. 2). At week three it was clear that sugar beet RLS treatments were stimulating greater hatch of $H$. schachtii than the control treatments. Significant differences were found between the total hatch of $H$. schachtii in response to RLS from different varieties of sugar beet (Fig. 2, $P<0.05$ ). Within the tolerant sugar beet varieties there was significant variation in total hatch of $\mathrm{J} 2$ observed after 6 weeks exposure to the RLS, with SB T 18 (18.2\%) being significantly lower than SB T 19 and SB T 17 (35.8 and 30.8\% respectively). However, there were no significant differences between the other varieties $(P>$ 0.05). The resistant variety RLS (SB R 14) elicited a significantly lower hatch (21.2\%) than SB T 19 and both the light tolerant varieties (SB LT 21 and 22) but was not different to any of the other treatments $(P<0.001)$.

The slower HR responses, despite greater levels of total hatch, show that the sugar beet treatments produced a more prolonged hatching period for $H$. schachtii than the water and sand controls. 


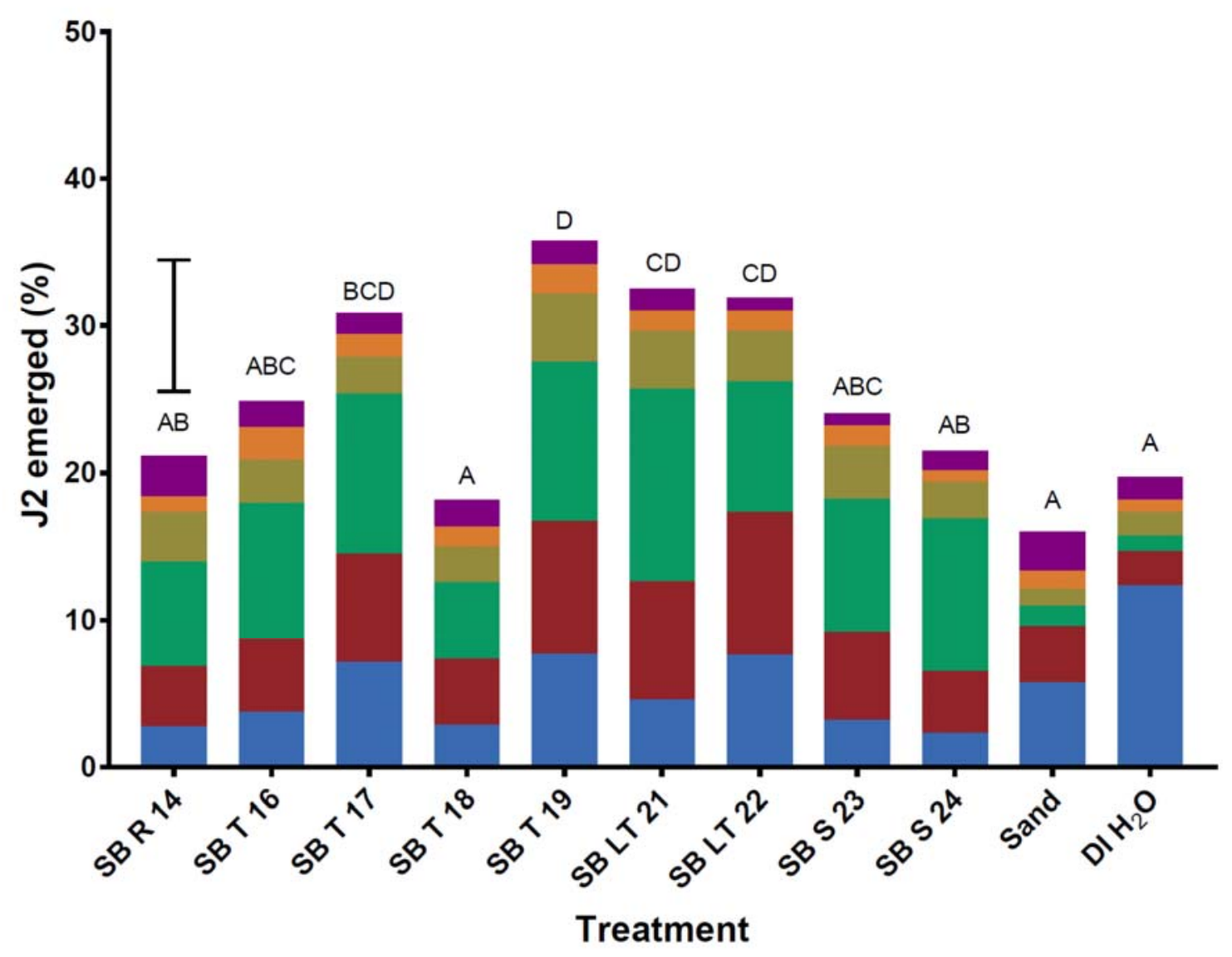

Fig. 2. Results of experiment using sugar beet treatments after 6 weeks of exposure to root exudate solutions. Sugar beet (Beta vulgaris) varieties grown were wither resistant (R), Tolerant (T), Light tolerant (LT) or susceptible (S) to Heterodera schachtii. Treatments are also labelled with their treatment number (Table 1). Control treatments of sand leachate and deionised water were also included. The bars show the cumulative percentage hatch counted every 7 days ( $\square 7, \square 14, \square 21, \square 28, \square 35$ and $\square 42$ days). Significant differences were found $(P<0.001)$ between the treatments. The error bar shows LSD at 5\% significance for the total percentage hatch recorded. Treatments with different letters show differences at 5\% significance according to Duncan's multiple range test. 
The sugar beet varieties resulted in similar responses in terms of HR by the H. schachtii J2 (Table 2), with SB LT 21, SB T 20, SB T 17 and SB R 15 resulting in similar HR to the water and sand controls $(P>0.05)$. The HR response of the $\mathrm{J} 2$ induced by the brassica treatments tested were also similar to one another, and the same as the sand and water controls (therefore indicating no effect on HR) but resulted in much greater HR responses than sugar beet treatments SB T 16 and SB S $24(P=0.001)$.

Different levels of cumulative hatch of $H$. schachtii J2 were found between the sugar beet RLS $(P<0.001)$, but there were no significant differences between the radish RLS (Fig. $3)$, which had a mean hatch level of $37.2 \%(P>0.05)$. All RLS treatments caused much greater levels of hatch than the deionised water or sand controls (mean of 5.0\%), most resulting in significantly higher levels of hatch. All radish RLS except R1, and all sugar beet RLS except SB R 15, resulted in significantly greater levels of J2 hatch and emergence than the sand control and only SB R 15 did not have greater levels of hatch than the deionised water.

Within the sugar beet treatments, the RLS of the resistant sugar beet (SB R 15) caused the lowest level of hatch (24.6\%). SB R 15 resulted in significantly lower hatch of J2 than the light tolerant variety treatment (SB LT 21) $(P<0.001)$, which caused the greatest level of hatch at $50 \%$. All of the other sugar beet RLS did not cause a significantly different hatch levels than either the resistant or light tolerant varieties tested (Fig. 3, $P>0.05$ ). 


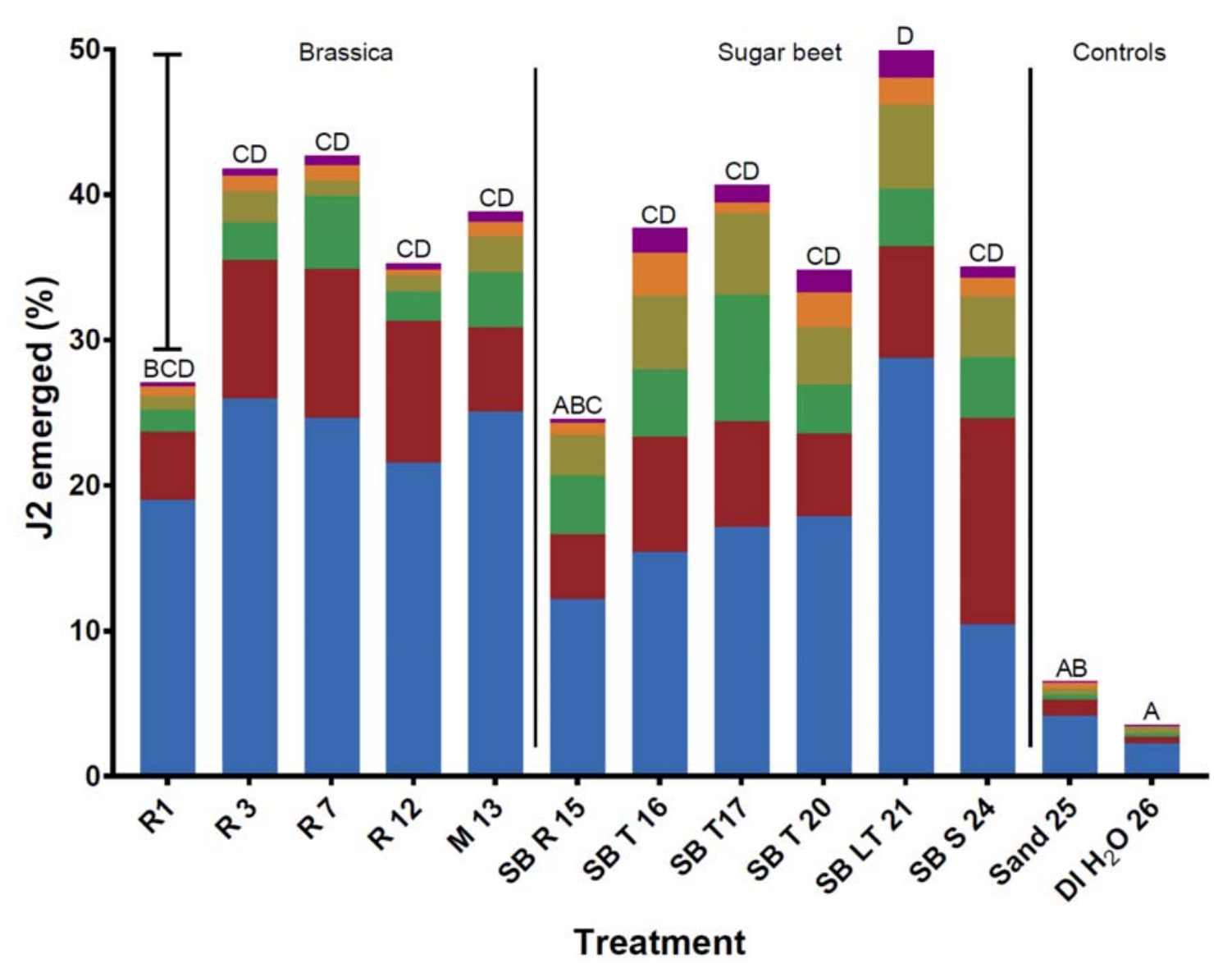

Fig. 3. Results of the combined experiment with brassica and sugar beet treatments after 6 weeks of exposure to root exudate solutions. The bars show the cumulative percentage hatch counted every 7 days ( $\square 7, \square 14, \square 21, \square 28, \square 35$ and $\square 42$ days). Significant differences were found $(P<0.001)$. The error bar shows LSD at 5\% significance for the total percentage hatch recorded. Treatments are labelled $\mathrm{R}, \mathrm{M}$ or $\mathrm{SB}$ for radish (Raphanus sativus), white mustard (Sinapis alba) or sugar beet (Beta vulgaris), respectively, and with their treatment number (Table 1). Sugar beet treatments are also labelled with their designation as Resistant (R), Tolerant (T), Light tolerant (LT) or susceptible to H. schachtii. Control treatments of sand leachate and deionised water were also included. Treatments with different letters show differences at 5\% significance according to Duncan's Multiple range test. 
In most cases, RLS from the radish, mustard and sugar beet varieties had a stimulatory effect on the total hatch of $H$. schachtii $\mathrm{J} 2$ after 6 weeks and a significant interaction between age and variety of plant was found $(P<0.001$; Fig. 4$)$.

With regard to the $H$. schachtii resistant radishes, RLS of R1 and R3 caused the greatest total hatch of $H$. schachtii when the leachates were collected from 6 week old plants. In the case of the R3 treatment, there was a significant decrease in $H$. schachtii hatch response to root leachates from the 7 week old plants $(P<0.05)$. For treatment R7, RLS from the 5 week old plants caused the greatest hatch, and then this significantly reduced with RLS from 6 week old plants. However, the response of the nematodes to RLS from the 7 week old plants was not significantly different to either of the 6 or 5 week old treatments $(P>0.05)$. RLS from radish R12, which is susceptible to $H$. schachtii, had a significant effect on stimulating J2 emergence regardless of the age of the plant when the leachates were collected.

The sugar beet variety control treatment RLS, susceptible to $H$. schachtii, was only seen to have a stimulatory effect on the hatch of $H$. schachtii when the RLS were collected at 7 weeks $(P<0.001)$, with the other two ages of plant resulting in similar hatch responses to the sand and water controls.

When the cumulative weekly hatch results were analysed (Table 3), a range of responses from the various treatments were found. Significant interactions between age of the plants and plant type were found each week $(P<0.001$ for all weeks). At 7 days (after the start of the experiment) clear differences were observed between the treatments. For example, RLS from the 5 week old R7 treatment induced very high hatch (59.1\%), which was greater than many of the other treatments. These distinct differences remained throughout the experiment, 


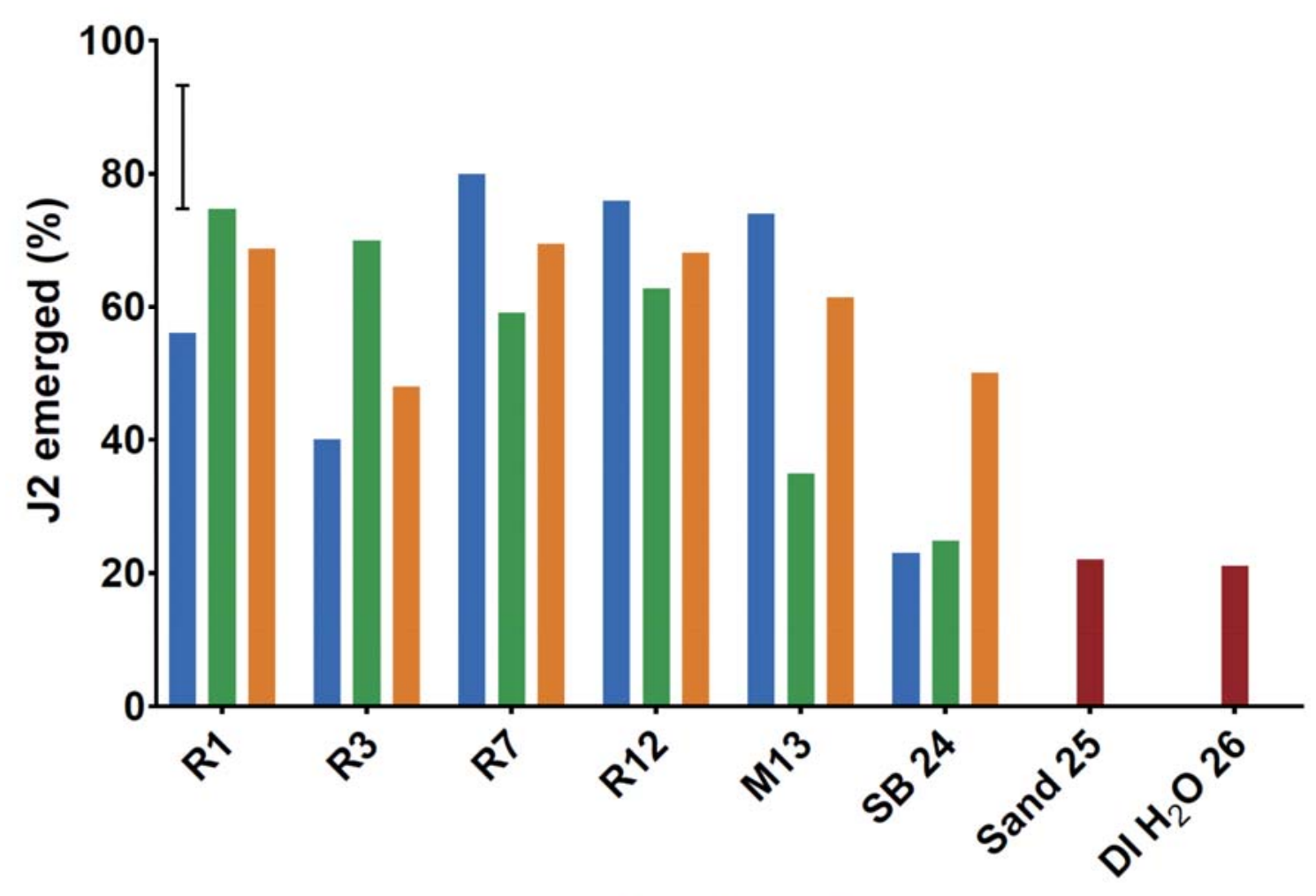

\section{Treatment}

Fig. 4. Total hatch and emergence of Heterodera schachtii second-stage juveniles (J2) following exposure to root exudate solutions. This experiment tested whether the age of the plant has an effect on the levels of hatch and emergence of $H$. schachtii J2. Root exudates were collected from radish, mustard or sugar beet plants (see Table 1) at $5 \square, 6 \square$ or $7 \square$ weeks after sowing. Sand and deionised water controls $\square$ were also included. Cysts of $H$. schachtii were then exposed to the root exudate solutions for 6 weeks and emerged J2 were counted at weekly intervals. Significant differences were found (Age $\times$ plant type interaction $P<0.001$ ) and the error bar shows LSD at 5\% significance for the total percentage hatch observed. 
1 Table 3 - Cumulative weekly percentage hatch and emergence of juveniles of $H$. schachtii in response to exudates of radish, mustard and sugar beet grown for either seven, six or five weeks in a controlled environment room. The experiment also included sand and deionised water controls. Different letters adjacent to the results indicate significant differences at 5\% probability according to Duncan's multiple comparison test.

\begin{tabular}{|c|c|c|c|c|c|c|c|c|c|c|c|c|c|}
\hline \multirow{3}{*}{$\begin{array}{l}\text { Treatment } \\
\text { R1 }\end{array}$} & \multirow{3}{*}{$\begin{array}{l}\text { Plant age (weeks) } \\
5\end{array}$} & \multicolumn{12}{|c|}{ Time of cysts' exposure to root leachate solutions } \\
\hline & & \multicolumn{2}{|l|}{7 Days } & \multicolumn{2}{|l|}{14 Days } & \multicolumn{2}{|l|}{21 Days } & \multicolumn{2}{|l|}{28 Days } & \multicolumn{2}{|l|}{35 Days } & \multicolumn{2}{|l|}{42 Days } \\
\hline & & 35.3 & cdef & 51.6 & defg & 55.2 & cde & 55.7 & cde & 56.0 & cde & 56.1 & cdef \\
\hline & 6 & 39.5 & defg & 68.8 & gh & 73.2 & ef & 74.0 & ef & 74.3 & ef & 74.7 & $\mathrm{fg}$ \\
\hline & 7 & 46.0 & efgh & 63.7 & efgh & 67.4 & def & 68.5 & def & 68.7 & def & 68.7 & defg \\
\hline \multirow[t]{3}{*}{ R3 } & 5 & 22.6 & abcd & 36.3 & $\mathrm{bcd}$ & 39.4 & $a b c$ & 40.2 & $a b c$ & 40.5 & $a b c$ & 40.6 & $a b c$ \\
\hline & 6 & 49.4 & $\mathrm{fgh}$ & 64.2 & efgh & 68.3 & def & 69.0 & def & 69.4 & def & 69.9 & efg \\
\hline & 7 & 29.9 & bcde & 43.6 & cde & 47.0 & bcd & 47.8 & bcd & 47.9 & $\mathrm{bcd}$ & 48.0 & $\mathrm{bcd}$ \\
\hline \multirow[t]{3}{*}{ R7 } & 5 & 59.1 & $\mathrm{~h}$ & 77.2 & $\mathrm{~h}$ & 79.8 & $f$ & 80.1 & $f$ & 80.6 & $f$ & 80.6 & $\mathrm{~g}$ \\
\hline & 6 & 44.7 & efgh & 55.5 & defg & 58.0 & cdef & 58.8 & cdef & 59.0 & cdef & 59.1 & cdefg \\
\hline & 7 & 43.0 & efgh & 64.9 & fgh & 67.7 & def & 68.8 & def & 69.3 & def & 69.4 & defg \\
\hline \multirow[t]{3}{*}{$\mathrm{R} 12$} & 5 & 48.9 & efgh & 65.7 & $\mathrm{fgh}$ & 74.4 & ef & 76.0 & ef & 76.6 & ef & 76.7 & $\mathrm{fg}$ \\
\hline & 6 & 42.4 & efgh & 59.7 & efgh & 62.2 & def & 62.6 & def & 62.8 & def & 62.9 & defg \\
\hline & 7 & 54.9 & gh & 65.9 & fgh & 67.2 & def & 67.6 & def & 67.8 & def & 68.1 & defg \\
\hline \multirow[t]{3}{*}{ M13 } & 5 & 54.6 & gh & 68.5 & $\mathrm{gh}$ & 73.2 & ef & 74.4 & ef & 74.6 & ef & 74.7 & $\mathrm{fg}$ \\
\hline & 6 & 19.6 & $a b c$ & 30.7 & $a b c$ & 34.6 & $\mathrm{ab}$ & 34.8 & $\mathrm{ab}$ & 34.9 & $a b$ & 34.9 & $a b$ \\
\hline & 7 & 38.8 & defg & 55.0 & defg & 58.6 & cdef & 59.4 & cdef & 60.8 & cdef & 61.4 & cdefg \\
\hline \multirow[t]{3}{*}{ SB S 24} & 5 & 13.8 & $\mathrm{ab}$ & 21.3 & $a b$ & 22.6 & a & 23.4 & a & 23.8 & $a$ & 23.9 & a \\
\hline & 6 & 11.0 & a & 19.3 & $\mathrm{ab}$ & 22.9 & a & 24.0 & a & 24.8 & a & 24.9 & a \\
\hline & 7 & 33.1 & cdef & 46.5 & cdef & 49.6 & bcd & 49.8 & bcd & 50.0 & bcd & 50.0 & bcde \\
\hline Sand & & 13.9 & $a b$ & 20.6 & $\mathrm{ab}$ & 22.5 & a & 22.6 & a & 22.6 & a & 22.6 & a \\
\hline Deionised $\mathrm{H}_{2} \mathrm{O}$ & & 5.6 & a & 13.3 & a & 18.9 & a & 20.9 & a & 21.6 & a & 21.7 & a \\
\hline$P$ & & $<0.001$ & & $<0.001$ & & $<0.001$ & & $<0.001$ & & $<0.001$ & & $<0.001$ & \\
\hline LSD & & 16.31 & & 18.05 & & 18.37 & & 18.46 & & 18.43 & & 18.46 & \\
\hline SED & & 8.15 & & 9.01 & & 9.17 & & 9.22 & & 9.20 & & 9.22 & \\
\hline$\% \mathrm{CV}$ & & 32.6 & & 25.7 & & 24.4 & & 24.2 & & 24.0 & & 23.9 & \\
\hline
\end{tabular}


with the brassica RLS all stimulating more hatch than the water control $(P<0.05)$, except M 13 at 6 week old, and R 3 at 5 week old $(P>0.05)$.

Differences were also found between the HR of the different treatments, and again an interaction between the age of the plants and plant type was found $(P=0.037$; Fig 5$)$. The 5 week old mustard (M 13) had a significantly greater HR than the 6 week old mustard and the 7 week old R 12 caused HR greater than the other two R 12 treatments. Other varieties, such as $\mathrm{R} 1$ and R 3, did not differ in their HR due to age of the plants. R 7 had the greatest HR at 6 week old and this was greater than the 7 week old plants. HR was reduced at 5 weeks but not significantly when compared to the 6 week old treatment $(P>0.05)$. The control treatments did not differ from each other in their HR. The sugar beet treatment (SB S 24) at 7 weeks had a greater HR than the water control but the remaining SB S 24 treatments were not different to the water $(P>0.05)$.

Biomass of the plants was found to increase with age in all of the treatments $(P=0.002)$, except for the mustard. The mustard plants at 5 and 7 weeks showed high levels of growth; however, the 6 week old plants did not show such vigorous growth (Fig. 6). RLS from the 6 week old white mustard had no significant impact on J2 emergence when compared to the control treatments $(P>0.05)$; however, leachates from the 5 and 7 week old plants did cause significant increases in H. schachtii emergence $(P<0.001$; Fig 4$)$. 


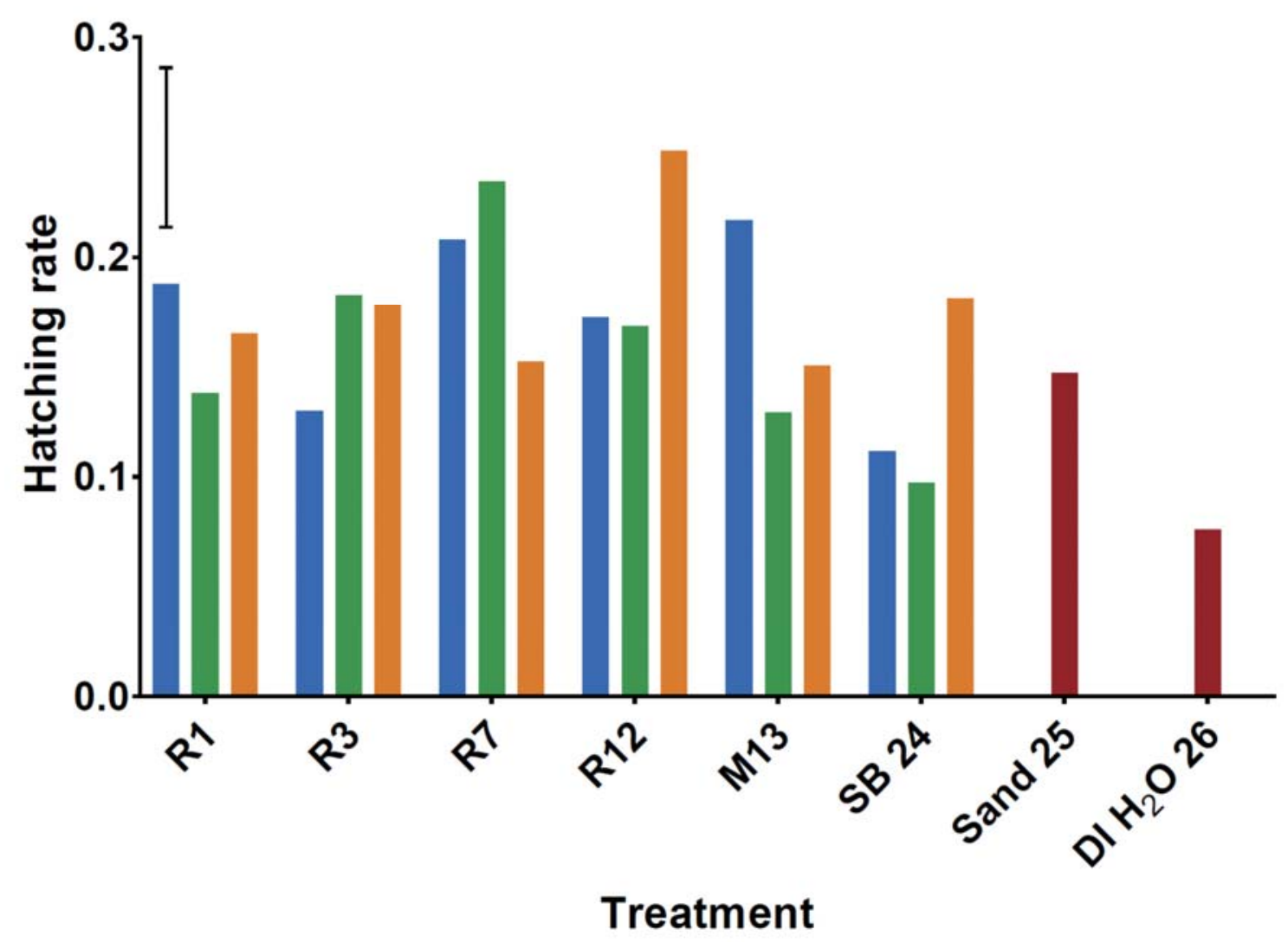

Fig. 5. Effect of brassica root leachates obtained from plants $5 \square, 6 \square$ or 7 weeks old upon the hatching rate (HR) of Heterodera schachtii second-stage juveniles from cysts after 6 weeks exposure to the root leachate solutions. The error bar shows LSD at 5\% significance (Age $\times$ plant type interaction $P=0.037$ ). Sand leachate and deionised water controls $\square$ were also included. 


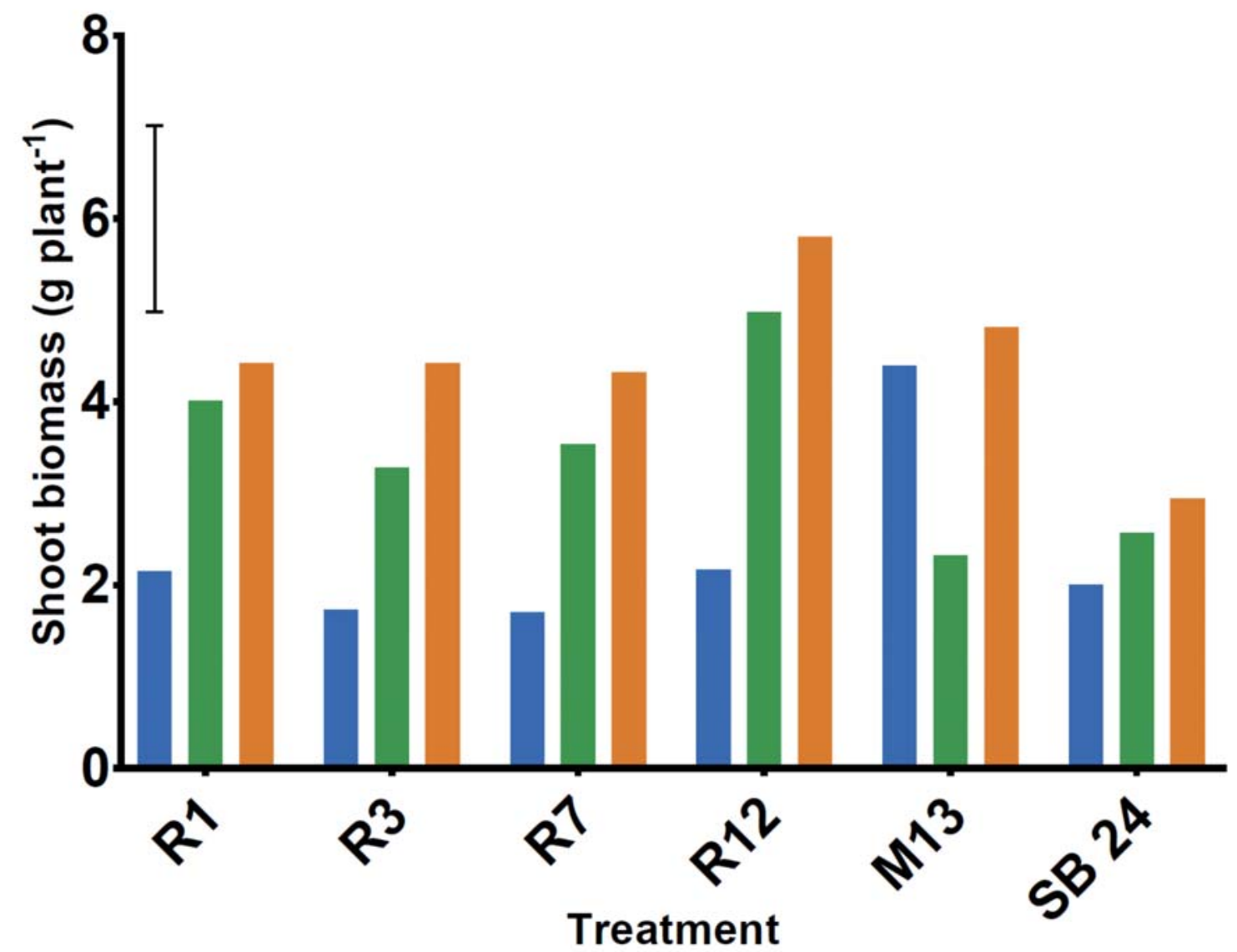

Fig. 6. Biomass measurements of shoot material harvested on the day of exudate collection. Material was dried until constant weight and then weighed. Plants were grown in a controlled environment room for either $5 \square, 6 \square$ or 7 weeks. Error bar shows LSD at 5\% significance (Age $\times$ plant type interaction $P=0.002$ ) 


\section{Discussion}

The stimulation of hatching of cyst nematode $\mathrm{J} 2$ is due to a number of physical, chemical and biological factors (Sharma \& Sharma, 1998). Important in the hatching process is the recognition of chemicals in host root leachates that stimulate hatch and emergence at an optimum point in the growth of the plant. These chemicals, known as hatching factors, are important as they lead to hatching of the $\mathrm{J} 2$ from the eggs inside the cysts. This is due to binding of calcium to the eggshells, resulting in a change in their permeability and subsequent movement of solutes, notably trehalose, from the egg fluid and thus the $\mathrm{J} 2$ is able to take up water and their hatch is stimulated (Perry, 2002). Hatching factors are produced in trace amounts (Masler \& Perry, 2018) and the response by the nematodes can be very specific to the age of the plant. For example, H. goettingiana has been shown to hatch in response to leachates from host pea plants between 4 and 6 weeks old (Perry et al., 1980) and H. carotae restricts its hatch to carrots aged between 5 to 7 weeks old (Greco \& Brandonisio, 1986). Age of brassica host plants has also been shown to influence the hatching activity of nematodes in $H$. cruciferae. Bowen (1988) showed that, despite continued growth of oilseed rape in both field and glasshouse experiments, the most stimulating point for hatching of $H$. cruciferae $\mathrm{J} 2$ was from plants 14 and 10 weeks old, respectively. In addition to the stimulation of hatch by host plants, they can also inhibit hatch (Masler \& Perry, 2018). Chemicals produced by the plants when they are immature and less suitable hosts for nematodes are detected by J2, which they interpret as a signal to delay hatch until the plant is better established, and therefore a more suitable host, resulting in greater fecundity of the nematode.

\section{BRASSICA HATCH RESPONSES}


The wider understanding of responses observed in other nematode species may help elucidate our observations, especially in response to the brassica varieties evaluated. Results from our first experiment investigating the response of $H$. schachtii hatching to brassica leachates were different to Experiments 3 and 4. Experiment 1 showed clear inhibition of hatching of $\mathrm{J} 2$ in response to the root leachates compared to the water control. This effect was clear in all of the brassica treatments when compared to the water control, with the most extreme inhibition being caused by treatment R7. However, Experiments 3 and 4 found enhanced hatch of $H$. schachtii J2 when exposed to brassica RLS. The results from the first experiment may be due to the extended storage of the leachates compared to the other experiments; activity of potato root leachates has been found previously to decline rapidly in the first 2 months (Widdowson, 1958) and this may have happened with our brassica root leachates. It is also possible that, despite being grown in the same CER for the same period of time, the plants instead produced inhibitory chemicals at the point of RLS collection. The different responses found may also be due to contamination with microbes during RLS storage, which may have degraded the compounds in the RLS and caused the responses observed. However, whilst we cannot fully explain this disparity between the experiments, the consensus of our findings in Experiments 3 and 4 shows that brassica root leachates do stimulate hatch of H. schachtii J2.

Experiment 4 highlights the influence of age of the plant on hatch of H. schachtii J2. Some varieties have shown to have an optimum age at which hatching is stimulated, and the HR that is stimulated can be influenced by the age of the plant when the RLS was collected,

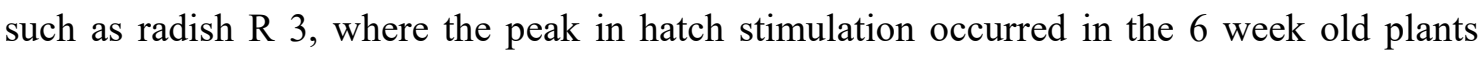
compared to the 5 and 7 week old plants. This agrees with the findings of Bowen (1988) that, regardless of the continued growth of the plants, their stimulatory effect is not increased. Other 
varieties, such as R7 and R 12 showed similar hatch stimulation regardless of plant age and size.

Our findings shed more light upon the hatching tactics of $H$. schachtii and future methods for control of field infestations. Understanding varieties that cause earlier and greater hatch of $\mathrm{J} 2$ could allow for varieties with the most prolonged hatch period to be selected by growers. Varieties such as R3, with their limited peak hatch period, may be less preferable to a variety such as R1 that shows more prolonged hatch. A variety that continues to stimulate $H$. schachtii hatch into the autumn would be of most benefit, especially in field conditions, where water availability may be limited in dry summers.

Brassica treatments R1 and M13 have recently been found to lower H. schachtii populations significantly in experiments in infested field (Wright et al., 2018). Populations were reduced by $30-40 \%$, which is lower than reported control levels of these varieties (Bundessortenamt, 2014). Other treatments, R3 and R7, also included in the field experiments, however, did not show significant population reductions. The findings from the current in vitro experiments may explain why these results occurred. The treatments that did not show control may have had limited peak hatch periods, or occurred at the wrong point in time to deliver a significant population reduction. Despite these results, it is also important to consider how a laboratory assay, using plants grown under controlled conditions and recently cultured cysts, may differ from field conditions. In the field, the conditions are less conducive to plant growth due to limited water availability, fluctuating temperatures, and pest and disease pressures. The interaction between these variations, the climate and weather conditions experienced in the field, soil type and age of the cysts in a field are far more complex than we could simulate in the laboratory. Studies using field cysts would be useful to validate our conclusions.

Variation in the responses could be a result of the different batches of cysts used from different cultures of $H$. schachtii. If in vitro tests were to be developed to further test $H$. 
schachtii hatching responses and evaluate future cultivars of sugar beet and brassica trap crops, the source of the cysts and their response to the biotic variations need to be standardised to ensure repeatable results and conditions.

\section{SUGAR BEET HATCH RESPONSES}

Our experiments have also shown consistent differences between the hatch of $H$. schachtii J2 in response to root leachates collected from different sugar beet varieties; however, further experimentation would be required to elucidate our findings and confirm these conclusions. It is interesting to consider that different batches of cysts appeared to respond differently to RLS obtained from the same varieties of plants, using the same methodology; enhanced standardisation is required, especially if this method is to be developed further. In Experiment 2, the sand and water controls resulted in similar final levels of hatch to the majority of the varieties, indicating that most varieties of sugar beet did not have a stimulatory effect on the hatch of $\mathbf{J} 2$. This was unexpected since $H$. schachtii juveniles have previously been shown to respond greatly to root leachates produced by suitable hosts (Perry, 2002). In Experiment 3 we observed clear stimulation of hatch, and therefore we hypothesise that differences in the age of the cysts between Experiments 2 and 3, may have caused these different responses seen to the RLS, with the RLS in Experiment 2 not resulting in hatching responses that were different to the water control, whereas in Experiment 3 a large response to RLS from the sugar beet was seen. Different responses in terms of HR have also been found between the experiments (Table 2). For example, the same cultivars of sugar beet resulted in much lower HR in Experiment 2 than in Experiment 3, supporting the hypothesis that different batches of cysts likely influence the differences found. 
The differences we have found between the varieties may not be conclusive enough to support a hypothesis that the tolerance or resistance level of a variety to $H$. schachtii is directly related to that variety's ability to stimulate hatch. It may be likely that other factors drive these differences instead. Wright et al. (2018) showed that light tolerant sugar beet varieties produced significantly greater root lengths when compared to resistant varieties grown in hydroponics. Therefore, the differences we have observed may be related to a physiological characteristic of a variety rather than its resistance or tolerance to $H$. schachtii.

Sugar beet growers with $H$. schachtii infested fields would usually select a tolerant variety to grow to protect yields $(\mathrm{BBRO}, 2018)$. From the information we have obtained from our investigations about the stimulation of hatching of tolerant sugar beet varieties, it appears that tolerance, and therefore maintenance of yield in $H$. schachtii infested situations, is not linked to reduced stimulation of hatching of $H$. schachtii J2. Therefore, tolerance is likely to be associated more with a reduced nematode hosting capacity of such varieties, as seen in other recent investigations (Hauer et al., 2016; Reuther et al., 2017). In addition, we have not found any clear distinction between the varieties in terms of the breeder who developed them, and cannot conclude that varieties from one breeder stimulate or reduce $H$. schachtii hatch differently when compared to varieties from other breeders.

Age and viability of the sugar beet plants does, however, seem likely to influence the level of $H$. schachtii hatch and therefore damage to the growing plants. In Experiment 4, we observed significant differences between the responses of $H$. schachtii $\mathrm{J} 2$ to root leachates collected from sugar beet plants of different ages. The larger and more mature beet plants elicited greatest hatch, whereas the 5 and 6 week old plants did not cause increased hatch over the controls. This supports our hypothesis that there is a relationship between sugar beet growth and the hatch of $H$. schachtii $\mathrm{J} 2$. However, future investigations into the response of sugar beet variety, 
age, development and subsequent stimulation of $H$. schachtii $\mathrm{J} 2$ hatch and emergence would be useful and may help with variety selection in the future.

\section{EXPERIMENTAL LIMITATIONS}

Whilst we have found differences in hatching in the experiments already described, it is worth noting that some of the responses are not as expected. For example, the cysts used in Experiments 1 and 2, produced much lower levels of hatching than the cysts used in later experiments. The response of these cysts differs from reported responses of $H$. schachtii to water and host plant root leachates (Perry, 2002), and was unexpected. This difference may therefore have caused the unexpected responses, especially the response to the brassica RLS in Experiment 1 and highlights the importance of repeating these experiments to obtain more conclusive results. In addition, increasing the number of replicates may help elucidate our findings and reduce the high levels of variation seen in these experiments.

Additional and unknown variation can also be seen in the results obtained when comparing the control treatments used in the experiments. For example, in the first experiment, the sand and deionised water treatments resulted in significantly different levels of hatch stimulation, with the sand appearing to inhibit hatch. Therefore, different growing mediums may interfere with the hatching process of nematodes, and this area requires further investigation. Differences in HR were also observed between the sand and deionised water treatments in Experiment 2, despite not existing in the other experiments. Again further replication, using greater numbers of cysts, may produce more definite results and allow for clearer conclusions to be made about $H$. schachtii hatching.

\section{CONCLUSIONS}


We have demonstrated that the hatching responses of $H$. schachtii in response to sugar beet, radish and white mustard are related to the variety being tested and can also be influenced by the age and development of the plant too. We have also highlighted the variability of working with cyst nematodes and suggest further replication of these experiments to clarify our findings. However, our results relating to root leachates from different sugar beet varieties show significant differences in the hatching dynamics of $H$. schachtii. Age and vigour of different varieties all appear to influence hatch of $H$. schachtii juveniles, although, variety type did not showing such definitive differences.

Finally, our findings also support the use of resistant trap crops to stimulate hatch of $H$. schachtii and thus reduce in field populations. We have shown that some varieties of these trap crops can maintain their stimulatory effect on hatch of $H$. schachtii J2s regardless of age of the plants, whereas other varieties have a shorter peak hatch period.

\section{Acknowledgements}

This project was conducted as part of a Ph.D. studentship jointly funded by the British Beet Research Organisation and The University of Nottingham. Additional financial support was also received from The Morley Agricultural Foundation. Jake Richards, Will Spracklen and Lou Dufour are thanked for their assistance collecting and preparing the root leachate solutions.

\section{References}

BBRO (British Beet Research Organisation) (2009). Beet cyst nematode technical guide. 
Norwich, Norfolk, UK, BBRO.

BBRO (British Beet Research Organisation) (2015). Recommended variety list 2016. Norwich, Norfolk, UK, BBRO.

BBRO (British Beet Research Organisation) (2018). Recommended list of sugar beet varieties 2019. Norwich, Norfolk, UK, BBRO.

Blok, V.C., Tylka, G.L., Smiley, R.W., de Jong, W.S. \& Daub, M. (2018). Resistance breeding, In: Perry, R.N. et al. (Eds). Cyst nematodes. Wallingford, Oxfordshire, UK, CAB International, pp. 174-214.

Bowen, S.A. (1988). Aspects of the population biology of the cyst nematode parasites of oilseed rape. Ph.D. Thesis, Luton, Bedfordshire, UK, Luton College of Higher Education.

Bundessortenamt (2014). Beschreibende Sortenliste: Getreide, Mais, Öl- und Faserpflanzen, Leguminosen, Rüben \& Zwischenfrüchte. Hannover, Germany.

CABI (2018). Heterodera schachtii (beet cyst eelworm), invasive species compendium. Available at: https://www.cabi.org/isc/datasheet/27036. (Accessed: 17 February 2018.)

Cooke, D.A. (1985). The effect of resistant cultivars of catch crops on the hatching of Heterodera schachtii. Annals of Applied Biology 106, 111-120. DOI: 10.1111/j.17447348.1985.tb03100.x

Cooke, D.A. (1987). Beet cyst nematode (Heterodera schachtii Schmidt) and its control on sugar beet. Agricultural Zoology Reviews 2, 135-183.

Danquah, W.B., Back, M.A., Grove, I.G. \& Haydock, P.P.J. (2011). In vitro nematicidal activity of a garlic extract and salicylaldehyde on the potato cyst nematode, Globodera pallida. Nematology 13, 869-885. DOI: 10.1163/138855411X560959

Dewar, A.M. \& Cooke, D.A. (2006). Pests. In: Draycott, A.P. (Ed.). Sugar beet. Oxford, UK, 
Blackwell Publishing Limited, pp. 316-350.

Evans, K. (1983). Hatching of potato cyst nematodes in root diffusates collected from twentyfive potato cultivars. Crop Protection 2, 97-103. DOI: 10.1016/0261-2194(83)900297

Fatemy, S. \& Abootorabi, E. (2002). Hatching activity, invasion rate and reproduction of Heterodera schachtii on oilseed rape cultivars. Nematologia Mediterranea 30, 163166.

Greco, N. \& Brandonisio, A. (1986). The biology of Heterodera carotae. Nematologica 32, 447-460. DOI: 10.1163/187529286X00327

Hauer, M., Koch. H.-J., Krüssel, S. \& Märländer, B. (2016). Integrated control of Heterodera schachtii Schmidt in Central Europe by trap crop cultivation, sugar beet variety choice and nematicide application. Applied Soil Ecology 99, 62-69. DOI:

10.1016/j.apsoil.2015.11.017

Jones, F.G.W. (1956). Soil populations of beet eelworm (Heterodera schachtii) in relation to cropping, Annals of Applied Biology 44, 25-56. DOI: 10.1111/j.1744-

7348.1956.tb06845.x

Kakaire, S., Grove, I.G. \& Haydock, P.P.J. (2012). Effect of temperature on the life cycle of Heterodera schachtii infecting oilseed rape (Brassica napus L.). Nematology 14, 855867. DOI: $10.1163 / 156854112 \times 631935$

Kakaire, S., Grove, I.G. \& Haydock, P.P.J. (2015). The number of generations of Heterodera schachtii completed on oilseed rape (Brassica napus L.) during the UK growing season. Nematology 17, 557-565. DOI: 10.1163/15685411-00002889

Koch, D.W. \& Gray, F.A. (1997). Nematode-resistant oil radish for control of Heterodera schachtii. Journal of Sugar Beet Research 34, 31-43.

Märländer, B., Hoffman, C., Koch, H.-J., Ladewig, E., Merkes, R., Petersen, J. \& Stockfisch, 
N. (2003). Environmental situation and yield performance of the sugar beet crop in Germany: Heading for sustainable development. Journal of Agronomy and Crop Science 189, 201-226. DOI: 10.1046/j.1439-037X.2003.00035.x

Masler, E.P. \& Perry, R.N. (2018). Hatch, survival and sensory perception. In: Perry, R.N. et al. (Eds). Cyst nematodes. Wallingford, Oxfordshire, UK, CAB International, pp. 44 73.

Müller, J. (1999). The economic importance of Heterodera schachtii in Europe. Helminthologia 36, 205-213.

Perry, R.N. (2002). Hatching. In: Lee, D.L. (Ed.). The biology of nematodes. London, UK, Taylor \& Francis, pp. 147-169.

Perry, R.N., Clarke, A.J. \& Beane, J. (1980). Hatching of Heterodera goettingiana in vitro. Nematologica 26, 493-495. DOI: 10.1163/187529280X00422

Reuther, M., Lang, C. \& Grundler, F.M.W. (2017). Nematode-tolerant sugar beet varieties resistant or susceptible to the beet cyst nematode Heterodera schachtii? Sugar Industry 142, 277-284.

Sharma, S.B. \& Sharma, R. (1998). Hatch and emergence. In: Sharma, S.B. (Ed.). The cyst nematodes. London, UK, Chapman \& Hall, pp. 191-216.

Shepherd, A.M. (1970). Extraction and estimation of Heterodera. In: Southey, J.F. (Ed.). Laboratory methods for work with plant and soil nematodes 5th edn. London, UK, HMSO.

Steele, A.E., Toxopeus, H. \& Heijbroek, W. (1982). A comparison of the hatching of juveniles from cysts of Heterodera schachtii and H. trifolii. Journal of Nematology $14,588-592$.

Widdowson, E. (1958). Observations on the collection and storage of potato root diffusate', Nematologica 3, 173-178. DOI: 10.1163/187529258X00391 
Winfield, A.L., Enfield, M.A. \& Foreman, J.H. (1987). A column elutriator for extracting cyst nematodes and other small invertebrates from soil samples. Annals of Applied Biology 111, 223-231. DOI: 10.1111/j.1744-7348.1987.tb01449.x

Wright, A.J.D., Back, M.A., Stevens, M. \& Sparkes, D.L. (2018). Evaluating resistant brassica trap crops to manage Heterodera schachtii (Schmidt) infestations in eastern England. Pest Management Science 75, 438-443. DOI: 10.1002/ps.5134

Zheng, L. \& Ferris, H. (1991). Four types of dormancy exhibited by eggs of Heterodera schachtii. Revue de Nématologie 14, 419-426. 